\title{
Titanium in Shipbuilding and Other Technical Applications
}

\author{
A.S. Oryshchenko ${ }^{1}$, V.P. Leonov ${ }^{1}$, V.I. Mikhailov ${ }^{1}$, P.A. Kuznetsov ${ }^{1}$, A.V. Alexandrov ${ }^{2}$ \\ ${ }^{1}$ NRC "Kurchatov Institute" - CRISM "Prometey", 191015, Saint-Petersburg, Russia \\ 2 JSC "Interstate Association TITAN", 121596, Moscow, Russia
}

Abstract. Aerospace industry is currently the major consumer of titanium in Russia. Shipbuilding is its second largest consumer. Oil and gas, chemical, pulp-and-paper and other industries use less titanium. In the Russian industrial sector titanium is getting more applicable. Since the $13^{\text {th }}$ World Ti-2015 Conference the titanium application trends have persisted [1]. Among the major development trends of titanium alloys one should note the development of titanium alloys for deep-water marine facilities, case designs of small-size nuclear power plants, the development of additive technologies, the technologies of isostatic pressing, the development of titanium products by new production facilities, etc. Titanium is still considered an advanced structural material used for scientific and technical progress in different industrial sectors.

Keywords: titanium, marine equipment, nuclear power engineering, shipbuilding

\section{Titanium in shipbuilding}

Over the last years the construction of large-size case designs of marine facilities made of titanium alloys has almost come to an end. Within this period Russia designed a few bodies of unmanned small-size research vehicles. There is no information on similar case designs manufactured by other countries.

Nowadays titanium is used in shipbuilding in designs of marine equipment and ship power engineering, such as:

- titanium ship systems that consist of pipes and shutoff valves, pumps and filters;

- desalination plants and drinking water tanks;

- propulsion systems (screw propellers, guiding devices and shafting);

- deck machinery (cargo booms, winches, etc.);

- exhaust systems cooled by sea water;

- heat-exchange units of the ship power;

- springs and fixing parts (bolts, screws, pins, etc.) (Fig.1).

Pipelines are the most widespread systems of marine engineering and power engineering. The wide range production of high-quality pipes made of titanium alloys and developed by Kurchatov Institute Research Center - "Prometey" Central Research Institute for shipbuilding was mastered in Ukraine in the Southern pipe plant located in the town of Nikopol.

The demand for titanium in shipbuilding has led to production of high-quality titanium pipes of the specified purpose by the Russian enterprises. 


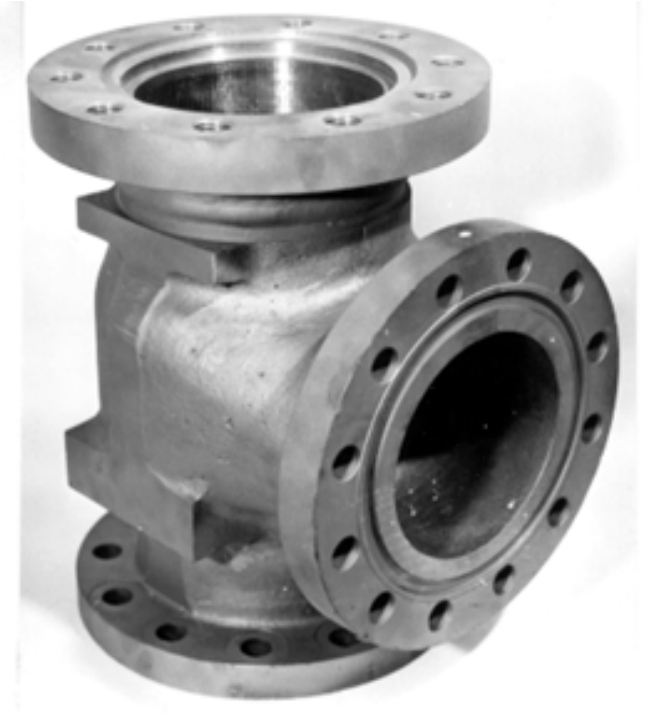

Fig. 1. Titanium valve body.

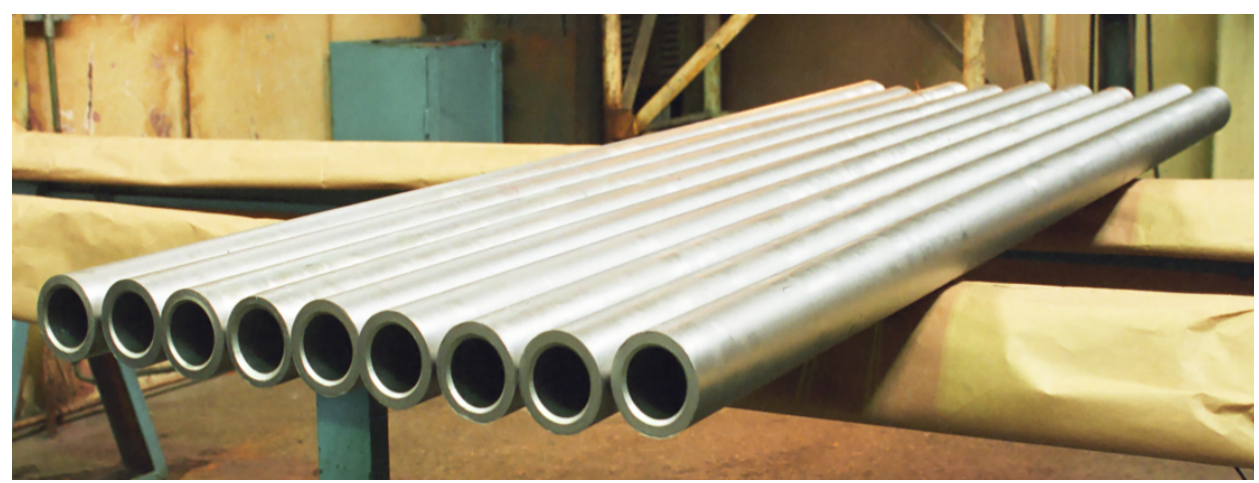

Fig. 2. Titanium tubes.

The study of the Russian pipe producing enterprises enabled us to select those being in full potential of manufacturing high-quality pipes made of titanium alloys for the ship power engineering and the shipbuilding.

By now the different purpose pipe production technologies have been developed and mastered (Fig.2) in Russia. For instance, such production facility located in Chepetsk Mechanical Plant ("ChMZ", located in Glazov), has developed the production of high-quality cold and hot formed tubes ( $\varnothing 3-325 \mathrm{~mm}$ ) through a complete metallurgical cycle: ingots melting, tubular billets obtaining, and tube production [1]. "VSMPO-AVISMA Corporation" located in the town of Verkhnyaya Salda manufactures both seamless pipes (up to $600 \mathrm{~mm}$ in diameter), up to $120 \mathrm{~mm}$ in thickness and welded $0.5 \div 1.2 \mathrm{~mm}$ thin-walled pipes.

It is well-known that the number of titanium applications is considerably limited by high cost of semi-finished products. Russia and other countries keep on reducing the cost of titanium products [3]. A major way to reduce it is to use secondary materials in the burden and economical alloying in combination with improvement of manufacturing technologies of semi-finished and finished products. Secondary material is a qualified waste and scrap used in the burden for ingots melting. To tackle the issue of economical alloying, Russia has developed a concept of economically doped alloys based on strictly rated additives of oxygen and nitrogen to obtain alloys of high strength and ductility [4]. USA and Japan have created economically doped alloys without expensive alloying elements to be used for civil industries [3]. Commercially efficient semi-finished production technologies based on electron beam remelting and powder metallurgy are being developed. Additive and isostatic pressing technologies for irregular shape manufacturing are also promising. USA, China, France and Germany are the leading developers of additive technologies [6]. 


\section{Titanium in nuclear power engineering}

Titanium alloys as structural materials used in heat-exchange equipment of transport nuclear power plants (multipurpose steam generators, condensers and heat exchangers) began to be widely applied after a positive service experience of steam generators when short-life steel materials had been replaced with corrosion-resistant titanium alloys.

The present day application experience of titanium alloys and the full scope of research of their service characteristics proved a wider use of titanium alloys for various systems of NPPs, including stationary ones.

Titanium alloys began to be used in turbine plants (blades of the final low-pressure cylinder stage, generator tread rings, oil cooling heat exchangers, condensers of refrigerators, pipelines of chlorination systems and other equipment.

The nuclear power engineering enables titanium pipes to be used with thinner walls than those made of corrosion resistant steels and copper-nickel alloys due to the lack of corrosive wear allowances. The applications of titanium pipes have also economic benefits, since they prevent power losses and ensure circuit purity of the source water. Equipment range expansion of titanium alloys used in nuclear power engineering is related with heat-transfer elements performance growth and their failure-free service life.

A way to increase the heat transfer indicators of heat-exchanging equipment made of titanium alloys, including steam generators is to use semi-finished products with extended surface like ribbed pipes.

Production of the ribbed pipes for highly effective steam-generators is being developed now.

In addition, some work is under way to replace steel with titanium in small and medium size reactor pressure vessels (RPV). Unlike steel, titanium has several technical, technological and economic advantages such as structure weight reduction, no anticorrosive cladding, minimum environmental impact, short repair time upon service life expiration, etc. Russia has a long experience of creation and operation of low power nuclear reactors used for shipbuilding. Integral type reactors are being designed today in which the entire primary loop equipment is encased inside a robust pressure vessel (Fig.3). Besides, such NPPs with a maximum amount of titanium can become basis of the power engineering in the Far North and the Far East regions. They can also support the oil and gas production, the Northern Sea Route and other hard-to-reach and extended areas and routes of Siberia.

Russia was the first to design a project of floating low power NPP, which is a new class of the nuclear power energy sources based on the Russian technologies of nuclear shipbuilding.

The first floating NPP named "Akademik Lomonosov" is equipped with two icebreaking-type reactor units that generate up to $70 \mathrm{MW}$ and $50 \mathrm{gkal} / \mathrm{h}$ of rated heat energy to meet the needs of a town with a population of 100,000 people. The floating NPP "Akademik Lomonosov" is a towed $144 \mathrm{~m}$ long and $30 \mathrm{~m}$ wide vessel that is now being tested in the port of Murmansk (Fig.4). By the end of 2019 it will be delivered along the Northern Sea Route to its operation site in the town of Pevek, Chukotka by the East Siberian Sea. 


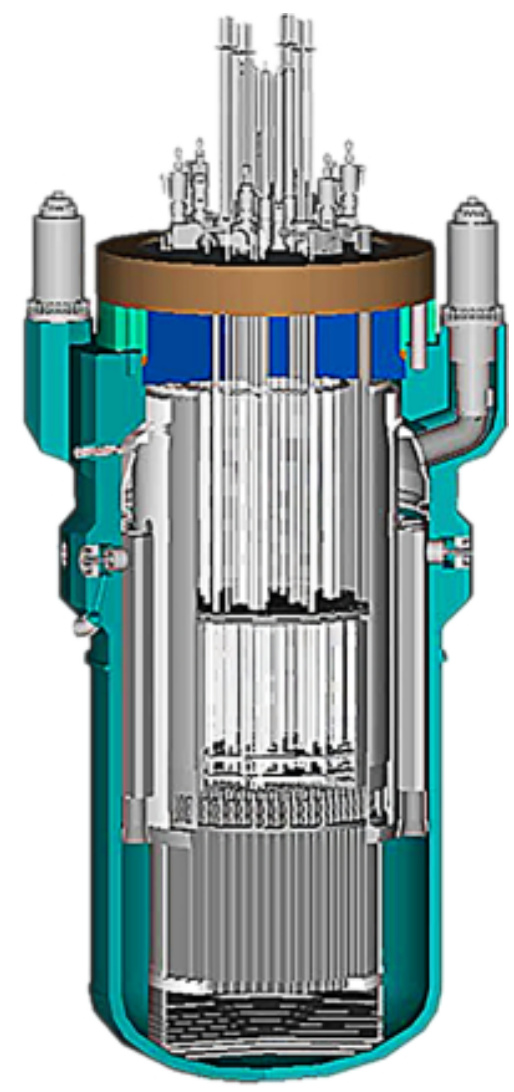

Fig. 3. Integral type reactor.

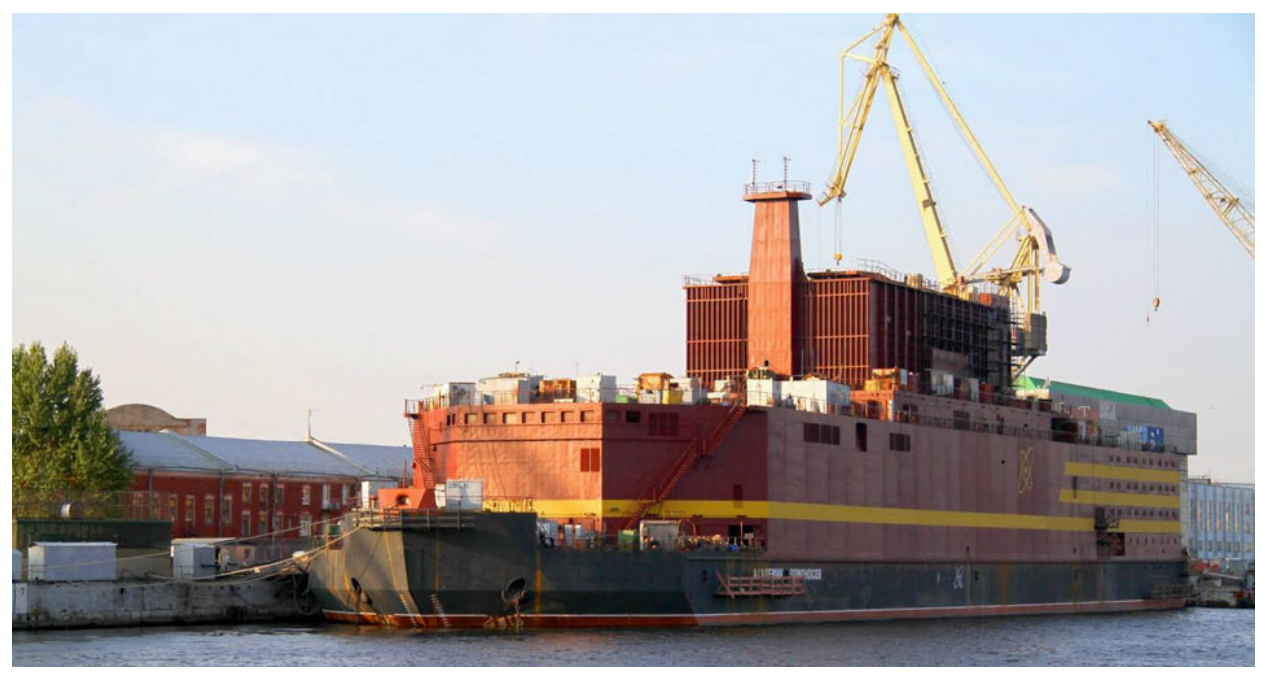

Fig. 4. NPP "Akademik Lomonosov".

\section{Titanium in other technical sectors}

The use of titanium in shipbuilding and the available engineering development can be efficiently applied for other industries, like oil and gas, chemical, pulp-and-paper, etc.

Russia possesses prolific oil and gas fields on the shelves of the Sakhalin Island, the Barents, the Karsky, and the Okhotsk Seas. The Russian Arctic sea stock is one of the biggest reserves in the world that exceeds all the available hydrocarbon resources in the Middle East. The modern drilling and extracting floating platforms are the complex self-contained structures (Fig.5). Elements, life support equipment and technological process have the same functionality as those in ships.

The use of titanium elements for platforms is significantly restricted by the Arctic climatic conditions, such as low temperatures (below $-60^{\circ} \mathrm{C}$ ), dynamic, corrosive and erosive influence of movable ice fields and 
wind loads. Besides, the structural materials have to be highly sustainable for ecological safety and high specific strength, considering that they are highly metal consuming.

Titanium alloys meet the specified requirements most of all in comparison with traditional materials that possess less reliability, specific strength and corrosion resistance. Titanium alloys can be used for the following oil and gas extraction equipment:

- pumps and intake systems of (sea), potable, drill and passing water;

- pipelines of circulating systems of technological solutions;

- stand-alone diesel fire pumps and fire extinguishing systems;

- tanks and reservoirs, including ballast systems. Fire and potable water systems;

- heat-exchanging equipment of different function, including desalinators, steam generators, refrigerators and cooling evaporators;

- flexible pipes of well equipment control;

- pressure vessels;

- high-strength flexible tension bracing used for the anchoring of deep water platforms.

Apart from the above-mentioned equipment, the use of titanium alloys is justified for riser systems and pressure piping to supply extracted products from underwater wells to platforms, vessel hoppers or transport ships. Low density in combination with high yield strength and fatigue resistance makes it possible to considerably decrease thickness of pipe walls and tension force of riser systems that need no floating elements in deep water. The use of titanium alloys in pipe systems makes it possible to enhance the designed flow speed, to reduce cross-section of pipes and material consumption of systems. Titanium becomes more advantageous as oil and gas production gets deeper, because deep drilling requires lighter drilling rigs.

Some properties of titanium can be attractive for production of directed drilling pipes, well tools, etc. thanks to the combination of its high specific strength and non-magnetism. Low modulus of elasticity is favorable for risers and flexible pipe systems. The growth of serviceability of equipment made of titanium and its alloys considerably adds to the operating expenses and service life of equipment up to the lifetime of platform or deposit field.

"Prometey" has developed a series of composite alloyed pseudo a - titanium alloys for marine applications of Ti-Al-V, Ti-Al-Zr, Ti-Al-V-Mo and other different categories of strength. These alloys possess high values of ductility and toughness of bulk semi-finished products, high workability in semi-integrated shipbuilding, high corrosion and crack propagation resistance in sea water, appropriate weldability without a subsequent heat treatment for stress relief. Service life of such equipment run in sea water is not less than 50 years. Many years of positive application experience of these alloys in shipbuilding have every reason to use them for various oil and gas production equipment. The use of titanium alloys in the elements of hydrocarbons producing off-shore structures helps extend their service life, which is sometimes close to the one of the deposit field itself, increase serviceability, cut operating expenses of service and repair, reduce the weight of platform equipment, and increase ecological safety. Pipe systems made of titanium of up to 400 tons in volume were used for the offshore platform named "Prirazlomnoye" in the Barents Sea. Some pipelines were subjected to the surface thermal oxidation to protect the steel structures against contact corrosion. Titanium alloys were widely used in equipment of oil and gas production platforms on the shelves of Norway, Alaska, the Gulf of Mexico, etc. 
The use of titanium in the structures and equipment of chemical, pulp and paper, and food industries is growing in production of:

- chlorine-containing compounds;

- organic acids;

- sulfuric acid;

- ammonia;

- oil processing products (petrol fractions), etc.

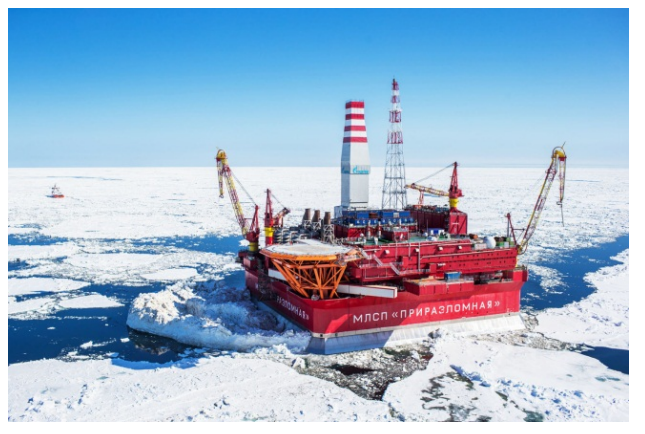

Fig. 5. Offshore platform "Prirazlomnoye".

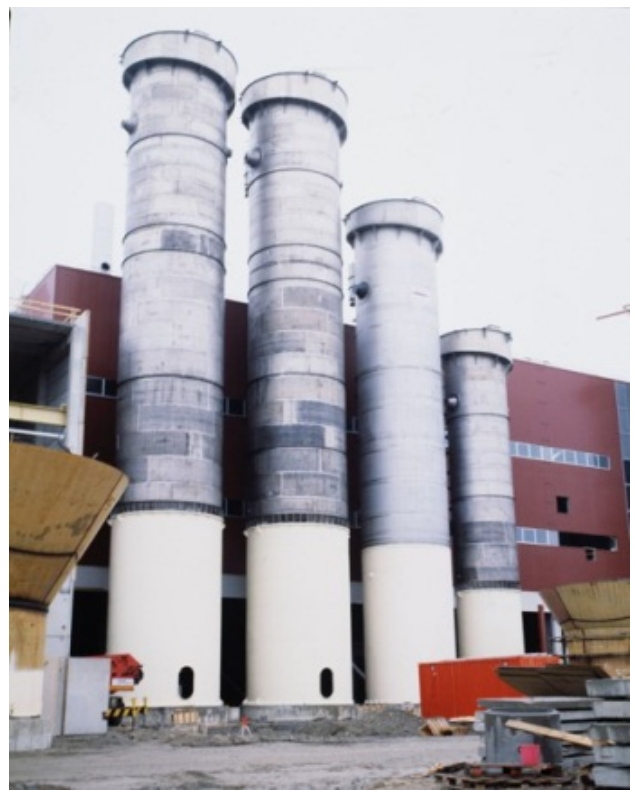

Fig. 6. Bleaching towers.

The use of titanium for food industry is caused by its excellent bacteriological and ecological properties. Storage tanks for juice, dairy produce, oil, wine, essence, and other food ingredients can be made of titanium.

Cellulose cooking (in acid or alkaline) and its whitening (in chlorine) are the basic manufacturing processes of the pulp and paper industry. Titanium is the best material to be used for the tanks (reactors, boilers and towers) in which these processes occur. "Prometey" has designed the technology and supported technically the manufacturing of bleaching towers by Baltic Shipyard (St. Petersburg) for a Finnish company. The towers had the form of cylinders up to $6.5 \mathrm{~m}$ diameter and up to $42 \mathrm{~m}$ high (Fig.6). Technical titanium in the grade of VT1-0 up to $20 \mathrm{~mm}$ thick was used as a base metal. Welding of the bleaching towers was 
performed by manual argon arc welding with VT1-00sv welding wire. Any service malfunctions of the bleaching towers have not been recorded.

\section{Summary}

When being developed, materials and production technologies go through different stages, such as creation, growth, advance and aging. Titanium alloys and their production technologies are on the advance stage nowadays [5]. It is featured by commercialization and cost saving of titanium production and products. In addition, titanium is still an advanced structural material that promotes scientific and technical progress of industries.

\section{References}

[1] I.V. Gorynin, A.S. Oryshchenko, V.P. Leonov, V.I. Mikhailov, I.A. Schastlivaya, Titanium Application in Marine Engineering and Nuclear Power Engineering, Proceeding of the $13^{\text {th }}$ World Conference on Titanium, San-Diego, USA, 2015.

[2] D.A. Negodin, D.O. Khlobystov, A.E. Moskalyov, et al., Results of Development and Production Mastering of Pipes Made of Titanium Alloys in CHMZ, Titanium-2018, №4, pp.37 - 45.

[3] G.A. Kolobov, V.V. Pavlov, A.V. Ovchinnikov, et al., Technology Aspects of Some Ways of Titanium Products Cost Reduction, Titan-2013, №3, pp.39- 44.

[4] N.A. Nogovin, A.V. Isaichev, V.G Antashev, Creation Issues of Efficient Titanium Alloys and Ways to Address Them, All Materials, Encyclopedia, Reference book, 2008, №5, pp.10 - 15.

[5] Yu.N. Kusakina, L.V. Fyodorova, The Use of Life Cycle Concept on Production Technologies for Perspective Scientific Research of Titanium Alloys, Titan-2017, №3, pp.50 - 53.

[6] A.V. Dub, Yu.N. Atipov, A.A. Popov, et al., Additive Technologies in Titanium Production, Titan-2018, №4, pp.31 - 35. 